Milica Mikuljević

\title{
New trends in employee education and training: the learning organisation
}

\begin{abstract}
This article is focused on the importance of accepting the modern concepts of operations based on knowledge management, and of organisations that learn and which are based on human capital, as the most important resource of today. This leads us to the conclusion that the main and predominant resources of the modern economy, right across the globe, are applied knowledge, education and science. Therefore, the construction of a society based on knowledge becomes a basic imperative of a global economy in which intellectual capital plays a lead role. Following a review of the argumentation behind the learning organisation, the author draws case study evidence on the issues raised from Telekom Srbje, which is on the start of the road to becoming a learning organisation, while arguing that professional, motivated and competent employees are not only an organisation's most valuable assets in the knowledge economy, they are a key source of a competitive advantage which competitors elsewhere will find impossible to replicate.
\end{abstract}

Keywords: knowledge management, organisational knowledge, society based on knowledge, intellectual capital, human resources, continuing professional development, competitive advantage, team working, communications

\section{Introduction}

Nowadays, we are witnessing turbulent, radical and dynamic changes in the field of socio-political relations but also in the field of economics and the fundamentals of an economy. All these changes require the adoption of new business philosophies and, in accordance with these, fully-fledged organisations prepared to accept modern operational concepts.

The concept of social development directed towards the knowledge society, at the centre of the mobility mechanism of modern development, puts individual workers and their knowledge of the application of information technology, and especially expert information systems, computer networks and the internet, at the heart of organisational operations. The centrality of the development of information and communications technology, production and the use of new materials, robotics, microelectronics, genetic engineering and other similar economic sectors has led to the ability to generate new knowledge, ideas, innovation and technology, as well as to the creation and disposal of human capital coming to represent a key determinant of a country's national wealth. So, instead of the previous concept of natural comparative advantages (natural resources, fertile land, mineral resources and available capital), as the determining factors in the growth rate and development of a national economy, there is the speed with 
which innovations can be created and the ability of an economy to translate acquired theoretical knowledge into new technologies.

The foregoing is confirmed by Peter Drucker in his book Innovation and Entrepreneurship (1996), which indicates that new technologies are represented not only by new materials, processes and activities, but also by new knowledge about the production process and the management of all the activities used in the modern business organisation, which is based on knowledge management.

We can say that all these intense changes in the environment, changes in regulatory requirements and the rapid development of technology are just some of the factors that have an impact on the operations of a company, as well as its competitive and market position. Consequently, the question is how to accept those changes and how to adapt to them or, in other words, how to go about meeting the challenges of the modern concept of business which is before us. The only real answer to such questions is to learn constantly, to educate and train - and not only individuals but also entire organisations.

\section{The need for a learning organisation}

Peter Senge, author of The Fifth Discipline (1990), in which he speaks about the ability and practice of learning organisations, points out that the competitive advantage of an organisation of any kind lies in its ability to learn faster than the competition: continuously to collect, share and increase knowledge between all employees as well as with its partners and customers. Nowadays, many organisations are aware that the only way to win and retain competitive advantage is 'to learn faster than the competition.' That is why a growing number of companies are trying to adopt and implement the concept of 'the learning organisation', in order to obtain advantage in a turbulent global market.

Learning organisations are prepared primarily to make quick responses to customers' needs and to master new technological developments and their applications, as well as to be ready for innovation and to adapt to changes coming from the environment. Within these, there lies the encouragement of learning and information exchange between employees, creating a more educated and productive workforce. Usually, organisational learning includes all those processes that are related to the acquisition of new knowledge, skills and behaviours within an organisation, while newlydiscovered successful solutions to management problems also become part of the knowledge base and of the management and the entire organisation. These organisations are involved in the creation, collection and transfer of knowledge as well as the modification of their behaviour in order to attain a specific new knowledge and vision that they will follow.

The learning organisation is always moving forward, because it is based on values such as continuous adaptation to change, the continual training of employees, the encouragement of creative and new ideas, and the development of the notion that the organisation as a whole is always more important than its individual parts. Additionally, it is based on an orientation that the organisation is 'without borders', which means the free movement of people, ideas and information leading to a reduction in barriers be- 
tween organisational units. That is, for the most part, because the culture of learning organisations creates a sense of community, equality and openness.

The main concept of a learning organisation can be applied to different organisational structures and sizes, involving systematic problem-solving, experimentation with new ideas, continuous learning and the modification of knowledge through experience. Based on these principles, Senge developed the concept of the learning organisation around the following concepts:

1. personal mastery: all employees are responsible for self-improvement and the expansion of their personal skills

2. mental models: the organisation that learns must create different mental models which will improve its competitive position

3. shared vision: shared vision is achieved by the integration of staff and a carefullyconstructed commitment to the group, achieved by directing the organisation to this end

4. team learning: employees working in a team, based on joint problem-solving and working together, will achieve organisational goals faster and more easily

5. thinking systems: expert problem-solving, systematic processes of research and communications and a system-based mindset helps us in understanding power relations and the internal behaviour of the system as a whole.

\section{Concept and characteristics of learning organisations}

According to research carried out at Stanford University (USA), the entire stock of human knowledge created up to 1900 had been doubled by the 1950 s. Since then, the store of human knowledge has doubled every 5-8 years. In the 1980s, Japan made a strategic decision to change its economic development strategy and, instead of investing in heavy industry, to focus investment on activities that are based on the human mind and knowledge. The results of such visionary decisions we see today.

At the beginning of the 21 st century, we are faced with the fascinating consequences of what new technologies have introduced in all areas of human activity. Intense technological development, the explosion of information in all sectors of the economy, the development of information and communications technology, and excellent dynamics in systems and their environment, have led to the emergence of learning organisations in which the knowledge of employees is the only permanent basis for competitive advantage. When the market changes, and when numerous technologies appear, competitors multiply and products become obsolete almost overnight, but successful organisations are those that continually create new knowledge, quickly spreading it throughout their systems. Such companies have realised that learning and new knowledge is becoming the key to success and that development is crucial to future survival. $^{1}$

A simple definition of the concept of the learning organisation is that it is an organisation whose employees are constantly learning new things and applying the lessons

1 Drucker, P (1993) Postcapital Society Harper Collins: New York, p. 201. 
learned to improve quality or the service offered. ${ }^{2}$ These are organisations in which learning is part of everyday business practice, as well as part of culture and existence. A significant part of its financial resources is invested in education and the dissemination of the knowledge of employees, who are its most valuable asset. Such organisations create assets which are sustained over time through learning by doing.

That is why the culture of learning organisations is based heavily on community, equality and openness. Part of this is that employees manage their knowledge so that they can adapt and exchange it on a mutual basis and that they are ready to apply it when making decisions or performing work.

An important part of a learning organisation is that new models of expansive thinking are developing, while collective co-operation encourages among employees the creation of a positive business climate. Put simply, the learning organisation is one which is skilled in the creation, adoption, development and the transfer of knowledge and which is capable of modifying its behaviour to reflect new knowledge.

An important difference between the traditional and the learning organisation is reflected in their different approaches to solving various problems. Traditional organisations are faced more with a hard focus on efficiency and the resolution of the problems of the present; while the learning organisation is primarily future-oriented and looking to resolve not only current problems but also potential ones in order to improve its efficiency and effectiveness in achieving its aims in the long-term.

Some of the basic and most important features of a learning organisation are:

- a high level of overall organisational development and knowledge, as it is constantly evolving and learning

- learning and development becomes a responsibility and obligation for all members of the organisation, and is an integral part of their job

- the transfer of learned and generated knowledge between all levels of the organisation becomes a part of everyday life and organisational culture in which all those engaged by it are, at one and the same time, employees, teachers and students

- assessment of the individual performance of employees is based on their effort and perseverance in acquiring knowledge, skills and abilities but also the continuous transfer of knowledge within the organisation

- learning and development in organisations becomes a way of life for employees and an essential part of organisational culture

- educational and developmental programmes for the acquisition of knowledge, as the most important capital in a learning organisation, represent the basis of its competitive advantages

- the culture of a learning organisation is one of continuous learning, and innovation and constant change, in which knowledge and creativity are rewarded

- the competitive and strategic advantage of learning organisations, in relation to their competition, is determined by the amount of knowledge, skills, abilities and talents of the human resources available

2 Noe, R. A (1991) Human Resource Management, Gaining a Competitive Advantage Burr Ridge: Illinois, p. 57. 
- these are organisations that learn by their own experiences, but also by the experience and practice of others; being ready and able to learn from others means that the competition is increasingly seen as a source of development opportunities.

In the era of knowledge, it is considered that each organisation must become a learning organisation in order to keep pace with the times. Also, learning is a continuous process of intensive interaction in which knowledge is spread and circulated in all directions, with all capable of adopting the roles of student and teacher. One important characteristic of learning organisations is that the continuing learning and development of its human resources becomes part of its organisational culture, while the cult of a business in which knowledge, as the intellectual capital of development, is increased, renewed and, most importantly, created, in order to survive in an unpredictable race with competitors at national and global levels, is represented by the embrace of continual change.

Figure 1 - Features of the learning organisation

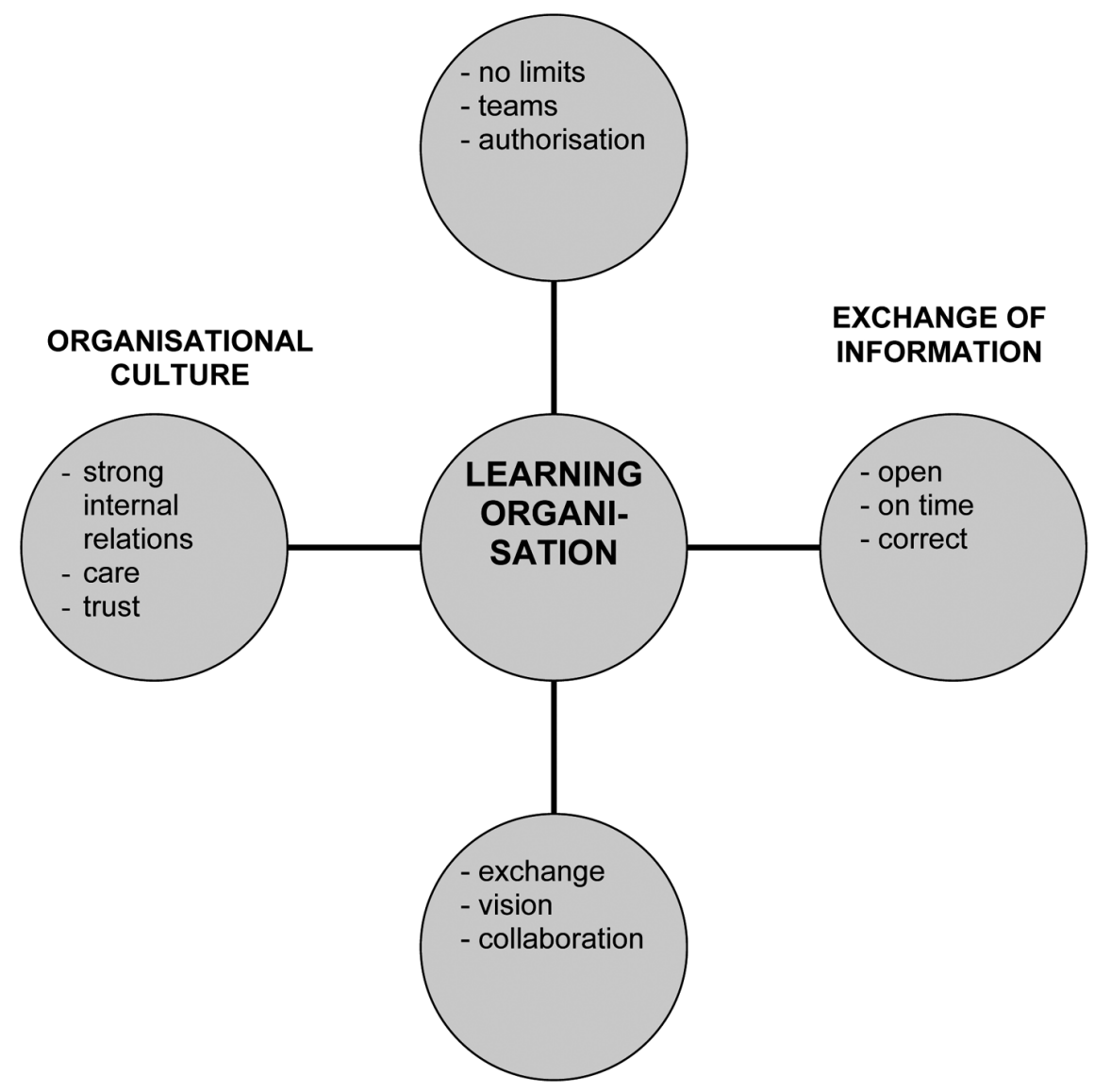


The richest and most developed countries of the world base their development strategy on industrial knowledge and investment in knowledge, and on improving the quality of education and the quality of jobs. Enterprises, the organisations of work, are the main bearers of economic development so it is clear that improving the quality of general knowledge depends on them. Such organisations, which represent a system whose members have passed through all common processes for continuous learning, retention and the encouragement of individual and collective sources of learning in order to improve the results of the organisational system, with the aim of continuous improvement and business results, are the only ones that can be greater and faster than the changes in their environment. The ability to learn faster than the competition is the only source of competitive advantage which is sustainable in the long-term.

In economics and management in the $21^{\text {st }}$ century, the complexity, unpredictability and high intensity of changes is the dominant factor. Consequently, the concept of the learning organisation is gaining in importance, so it is important to understand what is a learning organisation, what are its main characteristics and how it relates to the most important settings of knowledge management.

The learning organisation is a very appropriate concept for modern organisations which exist in a turbulent environment and are characterised by dynamism (frequent changes), complexity (a large number of factors that affect the company's operations), and a high degree of uncertainty of change. The learning organisation must be ready at any time to acquire new knowledge and experience.

This concept is not easy to adopt fully, but it cannot be denied that it has an important impact on the relationships of many organisations with their customers and employees, which makes the organisation more competitive and ready for new challenges. In such organisations, employees profit collectively at all levels by learning, developing and sharing new possibilities systematically. In short, it is an organisation that is constantly improving and becoming more successful, faster and smarter.

\section{Importance of intellectual capital for the development of learning organisations}

Doing business in a global environment that has completely changed the market, and given the strength of the forces of competition, dictates the survival terms of contemporary organisations in which only those who constantly encourage creativity and innovation and create new knowledge may survive. These features are characteristic of learning organisations that are mostly focused on human resources, hard data and information, as well as their research and development, in order continuously to create and expand knowledge, the indispensable and crucial resource of the $21^{\text {st }}$ century. Given that knowledge is today's main organisational resource, modern organisations are increasingly dependent on human resources, as the holders of knowledge, and less on others, such as financial and material resources. This leads us to the following question: how can organisations obtain and develop knowledge in the direction of achieving organisational goals? It is not enough just to establish knowledge in the organisation, but it is necessary that it is encouraged, developed and improved throughout the life of its employees. A special role in this process is taken by the management of modern organisations, especially in the context of knowledge management. 
Knowledge management has a major role in directing the collective knowledge of an organisation, including experience, competence, skills, data and information, towards employees at all organisational levels in order that they may perform their tasks more professionally and efficiently, and all with the aim of achieving the overall goals of the organisation. The essence of knowledge management is that it includes the human, organisational and technological factors that overlap each other, and that these can be applied to the development of internal knowledge and awareness from external sources, representing the most effective use of the intellectual capital of the organisation. This term has recently been receiving more attention in the literature of developed market countries, so there are number of definitions of 'intellectual capital' from different authors. However, what is common to all definitions is that this involves all the applicable knowledge in the organisation and which has practical benefits in creating a new quality and a new value for the organisation.

Intellectual capital has become an important factor in many businesses, and its deployment requires a different organisational structure. In organisations which have a bureaucratic organisational structure, with a large number of management levels and a strict division of labour, intellectual capital is not efficiently deployed. It comes to the fore, in contrast, in a value system that allows individuals self-affirmation through creative work, where they lose the importance of hierarchical symbols and where the need for constant supervision is eliminated. In other words, intellectual capital plays the largest contributory role in learning organisations, in which human resources are the most valuable organisational asset, since through their expertise, competence, knowledge, innovation and creativity, they are contributing to the achievement of the basic objectives of the organisation, i.e. the creation of value.

Intellectual capital - or, as many call it, intangible assets - often reaches a level of $80-90 \%$ of the asset base of organisations, which also reflects its importance as a factor in the success of many businesses. It is the main driver of innovation and competitive advantage in today's knowledge-based economy. The importance of intellectual capital for the development of learning organisations and other businesses is manifold:

- creating innovation and fostering creativity, processes that are difficult to imitate by competitors

- increased operational efficiency and effectiveness

- combining knowledge, skills and the experience of employees in the exercise of performance appraisal

- intellectual capital in the possession of a single organisation represents an important basis for the formulation of an effective strategy, since it significantly affects the creation of essential competence

- transforming knowledge into action or, in other words, benefits for the organisation (value added, new clients, better image, profitable product, new or improved product, etc.)

- in many industries and beyond, the market value of the organisation often depends on intellectual capital

- protection and defence.

Consequently, the importance of the intellectual capital of an organisation is reflected in its contribution to revenues from the sale of products and services; the rep- 
utation of the organisation; the reduction of costs; the creation of a barrier to entry of potential competitors; the creation of innovation and its protection; and so on. In the field of intellectual property protection, the management of learning organisations acts in two ways: offensively and defensively. Normal operation involves the creation of patents, brands and trademarks. Patents protect against the unauthorised use of innovations and such like, with sales of proprietary products and services allowing organisations to generate revenue. Brands serve organisations in the way of presenting themselves and their products and services on the market, while a trademark receives legal protection that prevents others from copying. This domain reflects the defensive value of the competitive position of the organisation, because a well-protected and wellknown brand in a given market creates barriers to entry as regards others.

We may conclude that intellectual capital plays the main role in the development of modern organisations that are increasingly becoming learning organisations. This constitutes the most valuable, intangible assets of an organisation, based on which value is created and competitive advantage generated in the modern market. Therefore, within learning organisations, knowledge, creativity and innovation become crucial values in achieving business success. Human potential, as a carrier of these values, becomes the most important resource of our time; in order that it may grow and develop, it needs constant investment. At the same time, the period of acquiring education is actually spread over the individual's entire life in the service of the organisation, expressing itself as a strategy of lifelong learning.

The reason for this is that it is today apparent that there is a direct correlation between each individual and the existence and social success of his or her standard of personal education. Of course, the presence of a growing number of educated individuals ultimately represents that the company has a stronger human and economic potential. $^{3}$

\section{Telekom Srbje - a learning organisation targeted at business improvement}

We have mentioned above that intense changes in the environment, changes in legislation and the rapid development of technology are just some of the factors that have an impact on the operations of a company, as well as on its competitive and market position. In this sense, the question is how to predict changes in this situation, how to adapt to them and how to meet the challenges that the modern concept of business poses to a company. The answer is to learn.

Learning is a continuous process and a prerequisite for the achievement of quality and a strengthening of the competitiveness of enterprises. Learning must be organised and, in this way, it may constitute an integral element of any good human resources policy. In this regard, a company must continually take actions that encourage and support learning. Training should be organised in every workplace, and education programmes should both be intensive and enable the continuous improvement of employees. 'Know how' and 'the production of knowledge' should become the key to the future of individuals, businesses and the wider community - characteristics of those

3 Marinković, V (2009) Ljudski resursi pred izazovima globalizacije Zadužbina Andrejević: Beograd, p. 24. 
who are able to think not only for today and tomorrow, but also as regards the future. ${ }^{4}$ This is the case mostly because development is not measured only by the resources available to a single company or, more broadly, to a country: more importantly, it is the quality of people who are discovering how such foundation elements are handled, processed and used.

Telekom Serbia (Telekom) was, for many years, characterised by a hierarchy of command and control in which a relatively small number of lower managers had the right to make decisions and held influence on the development of policy, with the aim of ensuring efficiency.

However, due to the accelerated changes that affect every modern company, including Telekom, organisational learning has become a vital organisational process. Through organisational learning, Telekom seeks to increase both the desire and the ability of its employees to understand the company in which they are employed and their environment, and that appropriate decisions contribute to the continuous improvement of its competitive position.

The progression from a traditional to a learning organisation is never a one-off process, even in the case of Telekom. The introduction of the new approach demanded a certain period of time, a large amount of money and significant personnel changes. It is well-known that progression from a traditional to a learning organisation may fail for several reasons, one of which is, most definitely, employees and their willingness to embrace new ways of working. Furthermore, five years ago in Telekom the average age of employees was high and it is at least perceived that, as we grow older, we become less willing to change.

However, a programme to encourage voluntary departures from the company, which has been successfully carried out for the last four years, while also leading to the employment of young professionals, has seen the average age shifted significantly downwards. This has had a major role in changing awareness among employees. New employees have brought new and creative ideas with their arrival, as well as contemporary approaches to problem-solving.

Young, talented people, eager for change, with new skills and training, have simply refreshed the company and seem to have 'shaken up' the other employees who quickly became aware that they had to accept new ways of working if they wanted to continue to be employed by such a company.

Telekom has gradually started to progress from being a traditional, vertical, i.e. hierarchical, organisation towards being a perfect, horizontal, i.e. network, one. This move has been based on a gradual authorising of employees to take management roles and the creation of a corporate culture that is focused on people. Alongside top managers, employees have delegated responsibility for decisions regarding the course of the work process and share in its design. Becoming responsible for so-called routine tasks, but not for creative decisions, was initially an act of employee empowerment which then laid down the basis for the establishment of a learning organisation.

4 Vemić, J (2007) 'Employee Training and Development and the Learning Organization’ Facta universitatis Series: Economics and Organization, Vol. 4 No. 2: 209-216. 
To become a learning organisation, Telekom carried out activities which sought to involve employees in the process of formulating the strategic direction of the organisation. Employees were engaged in joint efforts to formulate strategies and techniques aimed at finding a successful level of enterprise competitiveness. Thus, the strategy of the company became the result of the accumulated activities of teams of employees. Employees participated in resolving all the problems that arose. This had the effect of reducing the importance of formal boundaries between organisational units, as well as the border between the top and bottom of the company.

Telekom also introduced a new organisational structure, as we have mentioned, which was designed to be horizontal and thus enable employees more easily to perceive the company as a whole. This in turn allows them to formulate a unified vision of the entire company, to initiate changes and to help properly shape its future.

In this regard, it has encouraged co-operation between employees, as well as teamwork and better communications. Large departments with a manager at the helm were redesigned into smaller business units focused on innovation and flexibility. Small, highly-formalised divisions have been formed, contributing to greater speed, flexibility, responsibility and creativity of employees.

Telekom tends towards making communications within the enterprise as versatile as they can be, and it is considered that it is always better to provide more information, especially those related to financial results, new services, various proposals and ideas, productivity, and so on. Thus, the emphasis is on communications, particularly in information-sharing. Communications are multi-layered and include personal and e-mail communication, but also daily, weekly or monthly team meetings.

This information is also available to employees in the company's news sites, via various types of notices, decisions, regulations, procedures, internal magazines and the like. There is a specially-developed system of IT support, which is constantly improved and innovated by the installation of new software applications that facilitate work and improve the business.

It should be noted that Telekom, in addition to the above, is characterised by a specific organisational culture that fosters unity, equality, continuous improvement, openness and enthusiasm. Such a culture creates and fosters a sense of community and mutual concern among employees, as does the engendering of a network of human relationships that facilitate the development and advancement of employees to the fullest degree.

We have already observed that an organisation begins to learn when, first of all, its employees begin to learn: a company learns only through its employees. For a company that could benefit from the knowledge of its employees, it is necessary that they must first of all learn teamwork.

Teams are an integral part of all businesses, especially companies that are developing in the direction of becoming learning organisations. Telekom tends to make all important decisions among groups, with teams having been formed as the basic unit of learning. The team-learning ability of learning groups becomes bigger than the learning ability of any individual within the group. Collaborative learning is a process of a harmonisation of the developing team's ability to function as a whole, and to think and act in a new, synergistic manner, thus creating the results that its members truly want. 
In this sense, Telekom pays special attention to the personal development of employees. The personal and professional development of the individual is crucial to the success of the company. By learning emotional maturity, an understanding of the ethical and moral dimensions of the enterprise is increased. People who are personally experiencing and perfecting other changes in thinking learn to use reason and intuition. It is exactly this type of employee that Telekom requires - ones who are focused on group learning and are willing to engage in dialogue and productive discussion.

For the purposes of the professional development of Telekom employees, there are many types of training which have a special emphasis on continuous learning. In this regard, specific attention is given to courses that improve business skills, which is very important for employees who are in direct contact with the company's customers. Furthermore, employees are directed towards lectures, conferences, seminars, conferences and other professional events, both at home and abroad. These events are frequented by skilled experts, professionals and young talent from a range of different professions.

Furthermore, significant budgetary funds are allocated for continuing professional development and, above all, masters programmes, specialist studies and, to some extent, internationally-recognised $\mathrm{MBA}$ and $\mathrm{PhD}$ programmes. In addition, current programmes are also offered in the fields of information technology and foreign language courses for project management, as well as many other forms of education which are based on the maintenance of licenses to practise.

It can thus be seen that Telekom is consciously investing in its employees, while it is obvious that such an approach has been part of a long-term strategy. This strategy is supported by data obtained from numerous studies which have shown that the world's largest companies, including - for example - Motorola, benefit to the value of $\$ 30$ for each dollar they invest in training their employees. At the same time, it is clear that the surest way to achieve company profits and productivity is by treating employees as a value that needs to be developed.

It should be noted that special attention is also paid to the ongoing development and training of managers, given their importance in the management of an enterprise, with the intention of ensuring that they are included in training, seminars, conferences and other forms of professional development.

Drawing on the above, we can say that Telekom Serbia is striving to become a 'learning organisation' and to establish its employees as 'knowledge workers'. In this direction, it is tending towards applying the latest methods for the continuing education, training and development of employees.

Nevertheless, the size and complexity of Telekom mean that it is inevitable that parts of the company, especially in towns deep in the heart of Serbia, have resisted the application of the concept of the 'learning organisation', and for several reasons which we may outline as follows:

- first of all, some parts have retained a hierarchical structure, and as such, the next evolution of the Telekom organisational structure (which has already been announced as likely to happen over the next few months) will be modified and adapted around the concept of the 'learning organisation' 
- employees at certain levels of the company are not always willing to learn and do not see the connection between individual learning, increased productivity and competitive advantage

- an inadequate system of information and communications.

From the above, it can be concluded that Telekom is at the beginning of a road to becoming a 'learning organisation'. It is clear, at the same time, that incorporating specific systems and processes represents a lengthy and exhaustive process. Also, it is evident that the concept of 'learning organisation' is the only response to changes that are faster and require constant improvement and adaptation. In this sense, Telekom has a difficult task as regards creating amongst its employees a group of 'enlightened' people that are ready to develop their potential and share a vision of that with their teammates as a worthy goal. It is also important to highlight that, regardless of the severity of the path and the uncertainty of the success at becoming a 'learning organisation', Telekom has no choice but to continue moving in the direction of achieving this concept, since this is a sure way to become a more efficient company, with a higher rate of adoption of new ideas increasing productivity, leading to the company becoming more competitive and thus ensuring its survival in a turbulent market.

Therefore, it is indisputable that Telekom will turn, in the future, into a company that is seeking growth and prosperity. To assist such an approach, there is a need for essential employees who are able to cope with the speed and frequency of change, who possess special skills and competencies and who, as such, can provide an impulse to the business. Consequently, Telekom requires exceptional employees or, alternatively, talents. The ability to identify, recruit and retain, and 'cultivate' talented people, for the benefit of both individuals and the entire organisation, is the main prerequisite as regards its future success. Therefore, it is essential that managers who are responsible for managing and nurturing talent consider all aspects of their work and be properly trained in order that they may successfully carry out their duties.

In the case of Telekom, we can say that attracting talent is not a major problem. If what is emphasised at every seminar, conference or forum dealing with the topic of human resources - that companies are more successful if they manage people better is true, then, in that sense, the best companies do have the best people. We can say that Telekom tends to do exactly that - to have the best people. In order for a company to attract talent, it is necessary first of all to have an image. Telekom is a well-organised and well-governed company that had represented the pinnacle of success in business over many years. It invests significantly in the development and improvement of its employees and has extremely efficient training programmes which encourage each employee, within their capabilities, to reach their full potential. For these, and many other, reasons, Telekom is a very attractive company, especially to young, talented professionals who know that, by employment in Telekom, they would gain a lot more for themselves than they would in any other company in the country and beyond.

This is supported in that in the course of six months during the previous year, according to the 'First Chance' programme of the government of the Republic of Serbia, Telekom hired, for a limited period, 75 trainees, most of them highly-educated young people. This would have been their first job. When asked why they had signed up for Telekom, despite the range of competition, most responded that it was very important 
that their $\mathrm{CV}$ contained a reference to their being employed in such a renowned company.

\section{Conclusion}

In the new knowledge-based society, organisations are focusing on human capital as the most important part of intellectual capital, as it includes a combination of knowledge, skills, innovation and the ability of employees to fulfil their tasks, and reflects the values, culture and philosophy of the company. Intellectual capital is the prime mover of innovation and competitive advantage in today's knowledge-based economy and its importance to the organisation is reflected in its contribution to revenues from the sale of products and services, the reputation of the organisation, the reduction of costs, the creation of innovation and its protection, and so on. Such capital is the only intangible asset for modern organisations, and it is difficult for competitors to copy such assets on the basis that they themselves can provide a safer and brighter future in uncertain and ever-changing business conditions.

Professional, motivated and competent employees, who share the main goal of creating value for their company, are its most valuable assets; hence organisations' worldwide efforts to encompass the competences of their employees into a framework of collective knowledge, which remains the property of the organisation. This has led to the emergence of the theory of the 'learning organisation' as a new concept of modern business organisations in which learning is part of everyday business practice, as well as part of culture and organisations' very existence.

\section{References}

Drucker, P (1993) Postcapital Society Harper Collins: New York.

Garvin, D (1993) 'Building the Learning Organization' Harvard Business Review 71(4): 71-82.

Marinković, V (2009) Ljudski resursi pred izazovima globalizacije Zadužbina Andrejević: Beograd.

McGregor, D (1960) The Human Side of Organization McGraw-Hill: New York.

Noe, R. A (1991) Human Resource Management, Gaining a Competitive Advantage Burr Ridge: Illinois.

Nonaka, J (1991) 'The Knowledge Creating Company' Harvard Business Review 69(6): 96-104.

Vemić, J (2007) 'Employee Training and Development and the Learning Organization' Facta universitatis Series: Economics and Organization, Vol. 4 No. 2: 209-216. 